University of Nebraska - Lincoln

DigitalCommons@University of Nebraska - Lincoln

\title{
Standardization of RP-HPLC methods for the detection of the major peanut allergens Ara h 1, Ara h 2 and Ara h 3
}

\author{
Harmit Singh \\ California State Polytechnic University, harmitsingh@cpp.edu \\ Mary Jo Cantoria \\ California State University \\ Poonam Malave \\ California State University \\ Denny Saputra \\ California State Polytechnic University \\ Soheila Maleki \\ United States Department of Agriculture, Southern Regional Research Center, \\ soheila.maleki@ars.usda.gov
}

Follow this and additional works at: https://digitalcommons.unl.edu/usdaarsfacpub

Singh, Harmit; Cantoria, Mary Jo; Malave, Poonam; Saputra, Denny; and Maleki, Soheila, "Standardization of RP-HPLC methods for the detection of the major peanut allergens Ara h 1, Ara h 2 and Ara h 3" (2016). Publications from USDA-ARS / UNL Faculty. 1600.

https://digitalcommons.unl.edu/usdaarsfacpub/1600

This Article is brought to you for free and open access by the U.S. Department of Agriculture: Agricultural Research Service, Lincoln, Nebraska at DigitalCommons@University of Nebraska - Lincoln. It has been accepted for inclusion in Publications from USDA-ARS / UNL Faculty by an authorized administrator of DigitalCommons@University of Nebraska - Lincoln. 
Analytical Methods

\title{
Standardization of RP-HPLC methods for the detection of the major peanut allergens Ara h 1, Ara h 2 and Ara h 3
}

\author{
Harmit Singh $^{\text {a,* }}{ }^{\text {, Mary Jo Cantoria }}{ }^{b}$, Poonam Malave ${ }^{b}$, Denny Saputra $^{a}$, Soheila Maleki ${ }^{c}$ \\ ${ }^{a}$ California State Polytechnic University, Pomona, USA \\ ${ }^{\mathrm{b}}$ California State University, Los Angeles, USA \\ ${ }^{c}$ United States Department of Agriculture, Southern Regional Research Center, New Orleans, USA
}

\section{A R T I C L E I N F O}

\section{Article history:}

Received 18 September 2013

Received in revised form 6 August 2015

Accepted 8 August 2015

Available online 12 August 2015

\section{Keywords:}

Peanut

Allergen

HPLC

Ara h 1

Ara h 2

Ara h 3

Retention time

\begin{abstract}
A B S T R A C T
Crude peanut extract (CPE) was analyzed for three major allergens (Ara h 1, h 2, and h 3 ) using a $C_{12}$ and a $\mathrm{C}_{18}$ column at two wavelengths ( 280 and $220 \mathrm{~nm}$ ) and under different solvent conditions. HPLC profiles were compared for retention time, resolution, and peak heights. CPE samples were spiked with pure allergens to identify the peaks corresponding to allergens. The HPLC fractions of corresponding allergens were collected and freeze-dried in order to perform SDS-PAGE and immunoblotting tests. The best method was identified the one with a shorter retention time, better resolution, and greater peak height as compared with the other methods. In general, the peak heights were greater at $220 \mathrm{~nm}$ than at $280 \mathrm{~nm}$. The major disadvantage of the $\mathrm{C}_{12}$ column was the need for two sets of conditions to identify the allergens as compared to the $\mathrm{C}_{18}$ column where all three allergens could be identified in one run.
\end{abstract}

Published by Elsevier Ltd.

\section{Introduction}

Approximately $1.4 \%$ of Americans are currently allergic to peanuts, with the prevalence expected to increase in the future (Sicherer \& Sampson, 2007, 2014). Death, as a result of anaphylaxis, is more frequently as a result of peanut allergies than all other food allergies (Dodo, Marsic, Callender, Cebert, \& Viquez, 2002; Sicherer \& Sampson, 2010). A lifelong, strict avoidance of peanuts and peanut products is the current management technique recommended to for those who are peanut allergic (Wen, Borejsza-Wysocki, DeCory, \& Durst, 2007). Complete avoidance of all peanut containing products is extremely challenging given that peanuts are a ubiquitous food ingredients, making accidental ingestion likely (Maleki, Chung, Champagne, \& Raufmann, 2000). Even minute doses, as little as $100 \mu \mathrm{g}$, can trigger an allergic reaction underlining the potency of these allergens (Warner, 1999).

De Jong et al. (1999) identified a total number of six protein or protein subunits were recognized by more than half of the specific lgE-containing plasma samples of peanut allergic patients defining these as major allergens. Burks, Sampson, and Bannon (1998)

\footnotetext{
* Corresponding author at: Department of Human Nutrition and Food Science, California State Polytechnic University, Pomona, 3802 West Temple Ave, Pomona, CA 91768, USA.

E-mail address: harmitsingh@cpp.edu (H. Singh).
}

identified Ara h 1 and 2 to be a major concern since IgE from more than $95 \%$ of the peanut sensitive patients recognized this protein. Peanuts of different varieties and from different parts of the world contain similar proteins, including Ara $\mathrm{h} 1$ and Ara $\mathrm{h} 2$. Consequently, the IgE-binding properties are also similar, indicating that differences in serology of peanut allergy may not originate from differences in composition of peanut (Koppelman et al., 2001, 2003). The three major allergens belong to different categories of proteins; Ara h 1 is a vicilin-like protein (Pomes et al., 2005), Ara h 2 is a conglutin-homologue protein (Mills, Madsen, Shewry, \& Wichers, 2003) and Ara $h 3$ is a glycinin protein (Piersma, Gaspari, Helfe, \& Koppelman, 2005). Ara h 1 accounts for approximately $12-16 \%$ of total peanut protein content, Ara h $2 \sim 10 \%$ (Van Hengel, Anklam, Taylor, \& Hefle, 2007) and Ara h $3 \sim 25 \%$ of the total protein content (Chassaigne, Brohée, Nørgaard, \& van Hengel, 2007; Chassaigne, Trégoat, Nørgaard, Maleki, \& Van Hengel, 2009). The high abundance of these proteins in peanuts likely facilitates their detection.

The identification of peanut allergens is a multistep process. Initially, the defatted proteinaceous portion of the peanut, called crude peanut extract(CPE), is isolated (Lifrani et al., 2005; Moutete et al., 1995). The CPE is then subjected to SDS-PAGE and densitometry to quantify the amount of peanut allergens in the peanut protein. Recently, more complex techniques such as a combination of fluorescence two-dimensional differential gel 
electrophoresis, Western blotting, and Q-TOF mass spectrometry have been reported (Chassaigne et al., 2009).

Careri et al. (2008) have published a method using immunomagentic beads and LC MS to detect Ara h 3 and Ara h 4 proteins. All of these methods require rigorous sample preparation and relatively expensive LC system.

High performance liquid Chromatography (HPLC) has gained importance because of versatility and easier sample preparation, greater sensitivity, and comparatively easy training of personnel. Since Reverse Phase-HPLC (RP-HPLC) is a very sensitive, specific and simple, the development of optimum RP-HPLC conditions would be valuable for future researcher in preference to relying on multistep analytical techniques to detect peanut allergens. Pastorello and Trambaioli (2001) reviewed various methods for extraction and detection of allergens from animal and vegetable foods including ion-exchange gel filtration and reversed-phase chromatography. Francisco and Resurreccion (2009) used this technique to study phenolic compounds in peanut skin extracts. Previously, Moutete et al. (1995) published the first RP-HPLC detection of peanut allergens, however the authors did not specify which peaks corresponded to the major allergens Ara h 1 , Ara h 2 , and Ara $\mathrm{h} 3$. The goal of this study was to identify the peaks that correspond to Ara h 1, Ara h 2, and Ara h 3, as well as to standardize the method with the best resolution, wavelength and fastest elution time for their detection. $\mathrm{A} \mathrm{C}_{12}$ and a $\mathrm{C}_{18}$ column were chosen for comparison. Both columns are known for their high protein sample recovery rate, compatibility with a range of organic solvents, and ability to function at a wide $\mathrm{pH}$ range ( $\mathrm{pH} 1.0-10.0)$.

\section{Materials and method}

\subsection{Peanut samples and reagents}

Raw, unsalted, and unshelled US Virginia peanuts were generously provided by Harvest Manor Farms, LLC (Cedar Rapids, IA, USA). All reagents were obtained from Fisher Scientific (Pittsburgh, PA, USA) unless otherwise stated. Shinfield allergens were obtained from the USDA research center (New Orleans, LA, USA).

\subsection{Statistical analysis}

CPE samples were run in triplicate on alternate days to determine the variation in retention time, peak-peak distance and peak height between various methods. One-way ANOVA followed by Fisher's Least Significant Difference (LSD) tests were conducted using SAS version 8.2 to determine the best method for detecting peanut allergens using the $\mathrm{C}_{18}$ column. One-way ANOVA was conducted on data for the retention time of allergens, peak-peak distance (resolution from the allergen peak to the preceding protein peak) and peak heights. The best method for allergen analysis comprised increased sensitivity (absorbance), good resolution between allergen peaks, and faster retention time.

\subsection{Extraction of crude peanut extract (CPE)}

The method developed by Lifrani et al. (2005) was adopted with modifications. Briefly, $100 \mathrm{~g}$ of ground peanuts were suspended in acetone $(250 \mathrm{ml})$ and shaken for $1 \mathrm{~h}$ at $4{ }^{\circ} \mathrm{C}$. The acetone was decanted and discarded. The pellet left after washing with acetone was then suspended in diethyl ether $(250 \mathrm{ml})$, stirred, and allowed to settle. The diethyl ether was discarded, the extraction using diethyl ether was repeated four more times, and then the pellet was airdried for $24 \mathrm{~h}$. On the following day, an aqueous extract of the defatted peanuts was obtained by stirring the pellets for $20 \mathrm{~h}$ at $25^{\circ} \mathrm{C}$ in $0.1 \mathrm{~mol} / 1$ ammonium bicarbonate (adjusted to $\mathrm{pH}$ 8). The mixture was centrifuged for $80 \mathrm{~min}$ at $20,200 \mathrm{~g}$ and $4{ }^{\circ} \mathrm{C}$ (repeated $2 \times$ ). The supernatant was filtered using Whatman paper 1 , collected and then freeze-dried. The solid was labeled as crude peanut extract (CPE). Different batches of CPE were checked for consistency using RP-HPLC and SDS page according to the methods described by Moutete et al. (1995).

\subsection{RP-HPLC procedure for $C_{12}$ and $C_{18}$ column detection of Ara $h 1$ and Ara $h 3$}

The conditions published by Moutete et al. (1995) were used as the starting point for optimization experiments with modifications. A two-pump gradient was applied using a $\mathrm{C}_{12}$ and $\mathrm{C}_{18}$ column, $250 \times 4.60 \mathrm{~mm} 4$ micron Jupiter $4 \mu$ Proteo (Phenomenex, Torrance, CA, USA) for HPLC (Agilent, Santa Clara, CA, USA) analysis. The samples were eluted using two solvents; Phase A was a linear gradient of $0.05 \%$ trifluoroacetic acid (TFA) in water, and Phase B was $0-100 \%$ gradient of $0.05 \%$ TFA in methanol at $20 \mathrm{~min}$. A $1 \mathrm{~mL} /$ min flow rate and $100 \mu \mathrm{L}$ sample injection volume was used with 220 and $280 \mathrm{~nm}$ for sample detection. To identify allergen peaks in CPE in HPLC, pure allergens were added to a CPE sample and injected on to HPLC system; CPE was spiked with purified Ara $h$ 1 , Ara h 2, and Ara h 3 to monitor changes in retention times due to RP-HPLC flow rates and gradients.

The presence the allergens Ara h 1 and Ara h 3 were also verified using SDS-PAGE and immunoblots.

\subsection{RP-HPLC detection of Ara $h 2$ for $C_{12}$ Column}

Ara h 2 could not be identify with the $C_{12}$ column, using the conditions described in Section 2.4. Thus, conditions described in the method of Lehmann et al. (2003) were used to optimize detection with the $C_{12}$ column. The same conditions were used for Ara $h$ 1 and Ara h 3 analyses. The samples were eluted using two solvents; Phase A was a linear gradient of $0.1 \%$ trifluoroacetic acid (TFA) in water, and Phase B was $0-56 \%$ gradient of acetonitrile at $50 \mathrm{~min}$. A $1.5 \mathrm{~mL} / \mathrm{min}$ flow rate and a $100 \mu \mathrm{L}$ sample injection volume were applied and all samples were measured at $220 \mathrm{~nm}$ for 60 min per sample. Spike experiments with CPE and purified Ara h 2 were also performed, and SDS-PAGE and immunoblots were used to confirm Ara h 2 from the putative RP-HPLC fractions.

\subsection{Sodium dodecyl sulfate polyacrylamide gel electrophoresis (SDS-} PAGE)

The CPE fractions were mixed with $3 \times$ sample loading buffer (Invitrogen Corporation, Carlsbad, CA, USA), then incubated for $10 \mathrm{~min}$ at $65^{\circ} \mathrm{C}$. The proteins were separated on a 4-20\% Novex Tris- $\mathrm{HCl}$ pre-cast gel (Invitrogen Corporation, Carlsbad, CA, USA) and stained with Gel-Code Blue stain (Pierce, Rockford, IL, USA) for $1 \mathrm{~h}$, washed and photographed.

\subsection{Immunoblotting}

SDS-PAGE samples were electrophoretically transferred into a polyvinylidene fluoride (PVDF) membrane. The membrane was blocked for $1 \mathrm{~h}$ using 5\% blotto [5\% dry milk dissolved into phosphate buffered saline containing 0.5\% TWEEN (PBST)] to prevent non-specific protein binding. Chicken sera against Ara $h$ 1, Ara $h$ 2, and Ara h 3 (Sigma Immunosys, The Woodlands, TX, USA) were used as primary antibodies and were diluted in 5\% Blotto (1:5000), added to the membrane, and incubated for $1 \mathrm{~h}$. The membranes were washed $3 \times$ with PBST and incubated with the anti-chicken IgY horseradish peroxidase (HRP)-labeled secondary antibody (Sigma Chemical Company, St. Louis, MO, USA) at 1:10,000 dilution 
in $2 \%$ blotto for $30 \mathrm{~min}$. The membranes were washed $3 \times$ with PBST, $2 \times$ with PBS and incubated with ECL-Plus Western substrate (Amersham Bioscience Corp., Pistcataway, NJ, USA). The signal was then visualized using a CCD camera system (Fuji Photo Film Co., Ltd., Duluth, GA, USA). Magic Mark Molecular Weight Marker (Invitrogen Corp., Carlsbad, CA, USA) was used for Western blots according to manufacturer's instructions.

\section{Results and discussion}

Reverse phase $C_{12}$ and $C_{18}$ columns were compared in this study for the detection and resolution of three major peanut allergens Ara h 1, Ara h 2, and Ara h 3. HPLC conditions published by Moutete et al. (1995) and Lehmann et al. (2003, 2006) were used as starting points for this study. The peanut allergens were examined under various flow rates, wavelengths, and solvent gradients. Various conditions were rejected for high back pressure, too long a retention time, or poor resolution in the preliminary investigation. Table 1 is a summary of various methods that showed promising results for peanut allergen detection. Amongst the various methods mentioned in Table 1 , methods A, B, C and D at $280 \mathrm{~nm}$ were unable to show a clear peak corresponding to Ara h 2 using the $\mathrm{C}_{12}$ column (Table 2). Flow rates ranging from 1.0, 1.5, 2 and $2.5 \mathrm{~mL} / \mathrm{min}$ were examined during preliminary investigation. It was determined that, in general, flow rates above $1.5 \mathrm{~mL} / \mathrm{min}$ generated pressures above the set instrumental limit of $40 \mathrm{MPa}$. As presented in Table 1 only flow rates at 1.0 and $1.5 \mathrm{~mL} / \mathrm{min}$ were further investigated for Ara h 1 and Ara h 3 identification. The spike tests (Chassaigne et al., 2009) using pure allergen standards were conducted for all HPLC conditions to identify the allergen peaks in the chromatogram (Fig. 1). Peaks were expected to move under different conditions or overlap with other peaks; spike test was used as a quick way of identifying allergens peaks.

\subsection{RP-HPLC using $C_{12}$ column}

At the wavelength of $280 \mathrm{~nm}$, no baseline drift was observed for purified Ara h 1 and Ara h 3, as opposed to $220 \mathrm{~nm}$, and therefore $280 \mathrm{~nm}$ was used to identify these allergens. Ara h 2 was visible at $220 \mathrm{~nm}$ and was identified using a different set of RP-HPLC conditions ( $F$ and $G$ ).

The advantages of method A (Table 2) for Ara h 1 and Ara h 3 identification over that of Moutete et al. (1995) are that the retention times of Ara h 1 and Ara h 3 derived from CPE was halved by increasing the solvent B gradient (0.05\% TFA in methanol) to $100 \%$ in $20 \mathrm{~min}$.

Ara h 2 was only visible for methods F and G (Table 2) only. Method $\mathrm{F}$, the resolution was compromised by merged peaks

\section{Table 1}

Detection methods for CPE-derived Ara h 1, Ara h 2 and Ara h 3 used for both $\mathrm{C}_{12}$ and $C_{18}$ column; Gradient $1=100 \%$ solvent B at $20 \mathrm{~min}$; Gradient $2=100 \%$ solvent $B$ at $40 \mathrm{~min}$; Gradient $3=100 \%$ solvent B at $60 \mathrm{~min}$; Gradient $4=56 \%$ solvent B at $25 \mathrm{~min}$; Gradient $5=56 \%$ solvent B at $50 \mathrm{~min}$; Gradient $6=56 \%$ solvent $B$ at $75 \mathrm{~min}$.

\begin{tabular}{|c|c|c|c|}
\hline \multicolumn{2}{|c|}{ Method name } & \multicolumn{2}{|l|}{ Conditions } \\
\hline & Wavelength (nm) & Flow rate $(\mathrm{mL} / \mathrm{min})$ & Gradient \\
\hline A & 280 & 1.0 & $1^{*}$ \\
\hline B & 280 & 1.0 & $2^{*}$ \\
\hline C & 280 & 1.5 & $3^{*}$ \\
\hline D & 280 & 1.0 & $3^{*}$ \\
\hline $\mathrm{E}$ & 220 & 1.5 & $4^{* * *}$ \\
\hline $\mathrm{F}$ & 220 & 1.5 & $5^{* *}$ \\
\hline G & 220 & 1.5 & $6^{* *}$ \\
\hline
\end{tabular}

* Solvent $A=0.05 \%$ TFA in water, solvent $B=0.05 \%$ TFA in methanol.

** Solvent $A=0.1 \%$ TFA in water, solvent $B=100 \%$ acetonitrile.
Table 2

Retention time of three allergens with various methods using $C_{12}$ column.

\begin{tabular}{llll}
\hline Method & $\begin{array}{l}\text { Ara h 1 peak } \\
\text { retention time } \\
(\mathrm{min})\end{array}$ & $\begin{array}{l}\text { Ara h 2 peak } \\
\text { retention time } \\
(\mathrm{min})\end{array}$ & $\begin{array}{l}\text { Ara h 3 peak } \\
\text { retention time } \\
(\mathrm{min})\end{array}$ \\
\hline A & 16.1 & N/A & 16.3 \\
B & 28.9 & N/A & 17.4 \\
& & N/A & 29.4 \\
C & 35.1 & & 31.5 \\
& & N/A & 35.7 \\
D & 41.1 & & 38.8 \\
& & N/A & 42.1 \\
E & N/A & 26.0 & 45.1 \\
F & N/A & 29.2 & N/A \\
& & 30.0 & NA \\
& & 30.7 & \\
& & 31.5 & \\
G & N/A & 37.7 & \\
& & 42.2 & \\
& & 43.1 & \\
& & 44.4 & \\
& & 45.8 &
\end{tabular}

* Method $\mathrm{F}$ and $\mathrm{G}$ detect Ara h 2 with several peaks using $\mathrm{C}_{12}$ column.

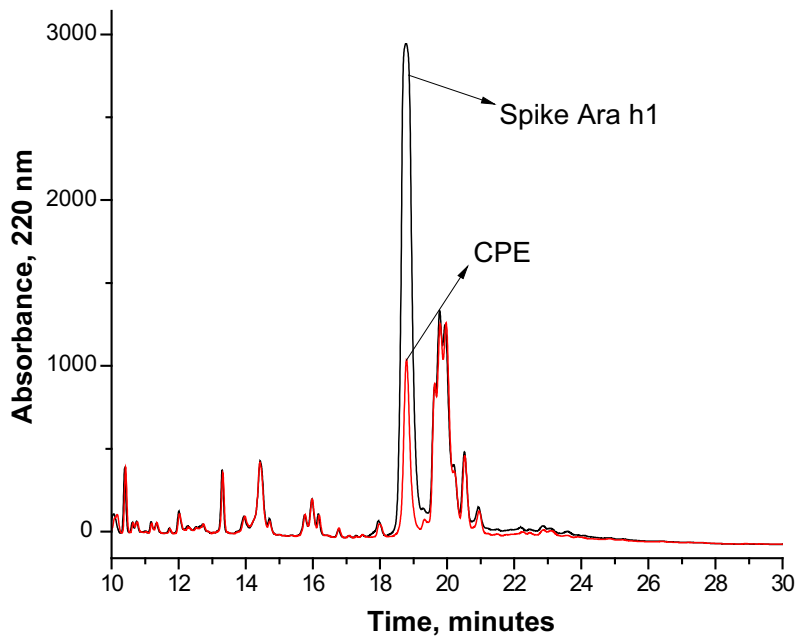

Fig. 1. Example of HPLC chromatogram of spike experiment conducted by adding purified allergen solution (Ara h 1 in this case) in CPE to identify the allergen peak position.

arising from the more rapid shift in solvent B gradient. Ara h 2 was appeared as multiple peaks for both methods, 26.0-32.0 min for methods F and 37.7-45.8 min for method G.

\subsubsection{Peak collection and analyses of data from $C_{12}$ column}

To verify the purity of the Ara h 1 and Ara $h 3$ peaks using method A (Table 2), fractions were collected as illustrated in Fig. 2A. Each fraction was analyzed by SDS-PAGE (Fig. 2B) and immunoblots using anti-chicken IgY specific for Ara h 1 and Ara h 3 (Fig. 2C) to confirm that RP-HPLC peaks indeed contained Ara h 1 and Ara h 3. Ara h 1 was present in fractions 2, 3, and 4 while the Ara $\mathrm{h} 3$ subunits were found in fractions 3 and 4 (Fig. 2B and C). Both SDS-PAGE and immunoblots verified that the proteins with peak retention times 16.2, 16.6 and 17.6 min contained Ara h 1 and Ara h 3.

Similarly, fractions of CPE were collected using method F (Table 2) and analyzed by SDS-PAGE and immunoblots to verify the presence of Ara h 2 (Fig. 3) in the putative RP-HPLC peaks. 
(A)

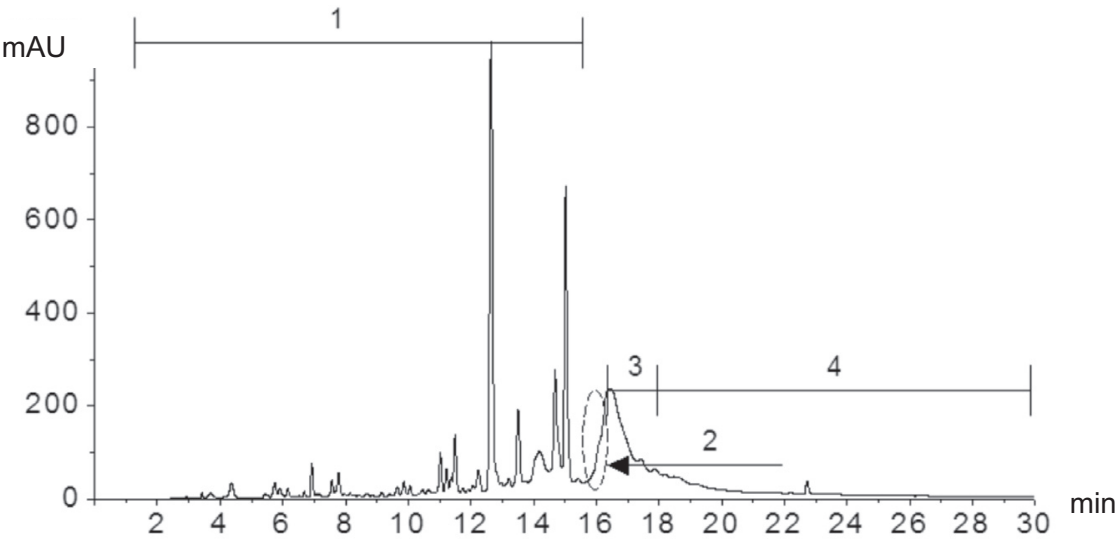

(B)
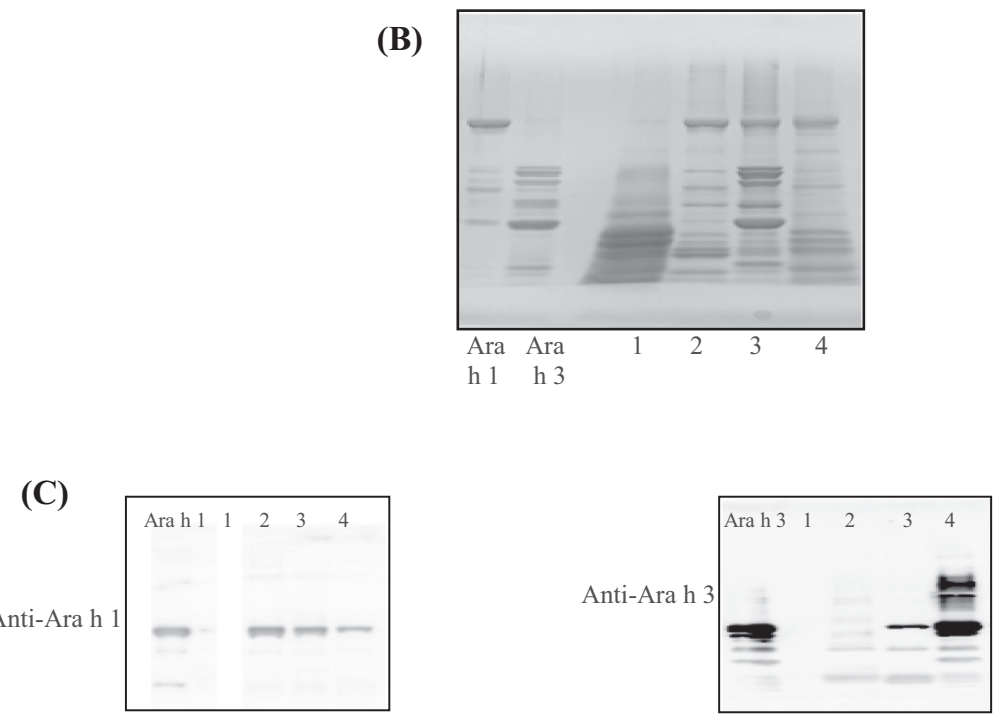

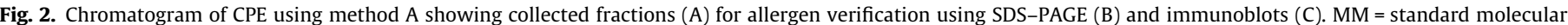
weight marker.

Out of the five fractions, B2 and C2 contained the majority of Ara h 2 as illustrated by SDS-PAGE (Fig. 3B) and immunoblots (Fig. 3C).

SDS-PAGE and immunoblots showed that peaks from 26.5 to 32 min were Ara h 2, although the exact identity of the smaller peaks needs further research. We chose method $\mathrm{F}$ for more efficient identification of Ara h 2 . However, method G gave better resolution of the four smaller peaks from 29.5 to $32 \mathrm{~min}$, and would be more useful if trying to isolate the four peaks for the purposes of purification and identification.

\subsection{RP-HPLC using $C_{18}$ column}

The major advantage of using the $\mathrm{C}_{18}$ column was in the identification of all three allergens using a single method as compared to the $\mathrm{C}_{12}$ column in which Ara h 2 was not clearly separated using methods A to D (Figs. 4 and 5). Results of CPE analysis using methods A-D and E-G are tabulated in Tables 3-5. During our study with the $\mathrm{C}_{18}$ column, we observed that $\mathrm{CPE}$ analyzed with methods $E$ to $G$ (absorbance at $220 \mathrm{~nm}$ ) yielded a higher absorbance of allergens compared to methods A-D (absorbance $280 \mathrm{~nm}$ ). Among methods $A-D$, the fastest retention time and maximum peak heights for allergen analysis was obtained by method $A$, while method $\mathrm{D}$ showed the maximum peak-peak distance for the 3 allergens (Table 3).
During CPE analysis by methods E-G, it was observed that Ara $\mathrm{h}$ 3 was eluted as a set of 3 peaks. Thus, data for retention time and peak heights for all 3 peaks was collected and analyzed. The distance from the highest allergen peak to preceding peak was measured for Ara h 3. Amongst methods E-G, method E showed the shortest retention time of the three allergens, maximum peak height for Ara h 1 and Ara h 3, and maximum peak-peak distance for Ara h 2. The maximum peak-peak distance (resolution) for Ara h 1 and Ara h 3 was observed with method $G$ while method $F$ yielded a maximum peak height for Ara h 2 analysis (Tables 4 and 5).

In summary, although method A had the shortest retention time for allergens, it was lacking in peak height (absorption) and peakpeak distance compared to method E. Methods D and G showed maximum peak-peak distance but the shortcoming with these methods was a long retention time, decreased peak height, and some baseline drift compared to method E. Method E was chosen as the best method for peanut allergen detection using a $\mathrm{C}_{18}$ column. Method E eluted Ara h 1 and Ara h 2 as individual peaks at 18.6 and $14.4 \mathrm{~min}$, and Ara h 3 was eluted as a set of 3 peaks ranging from 19.2 to $21.2 \mathrm{~min}$.

\subsubsection{Peak collection and analysis of data from $C_{18}$ column}

The allergen peaks identified after spike test samples were collected and freeze dried, and analyzed by SDS-PAGE and 
(A)

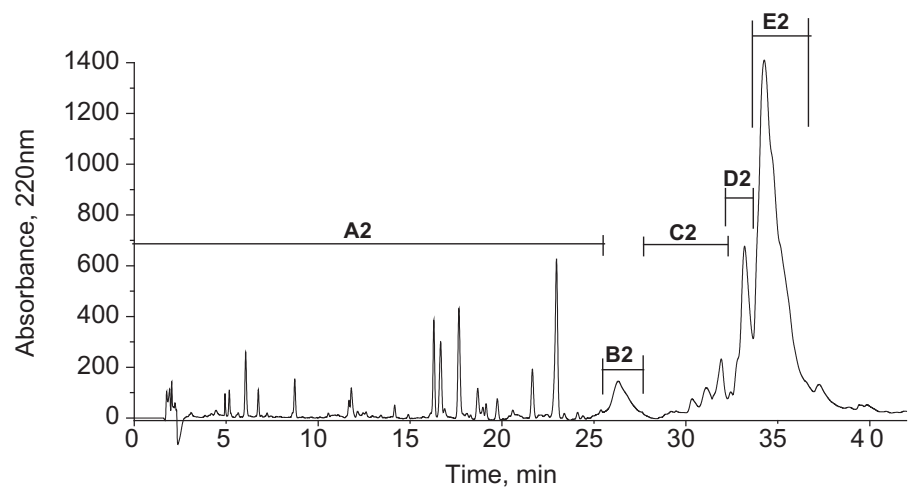

(B)

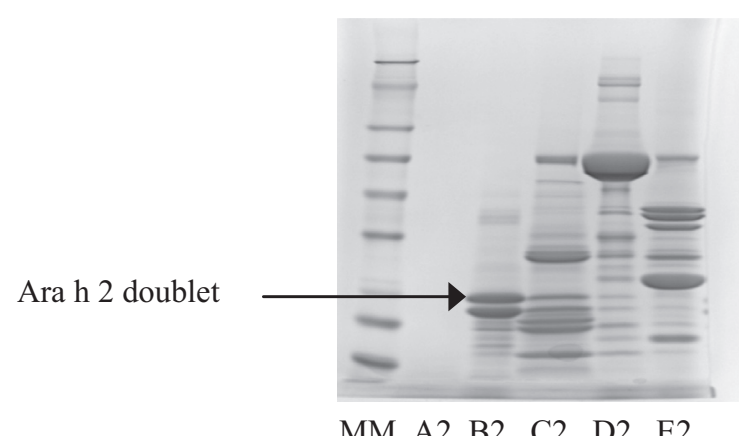

MM A2 B2 C2 D2 E2

(C)

Ara h 2 doublet

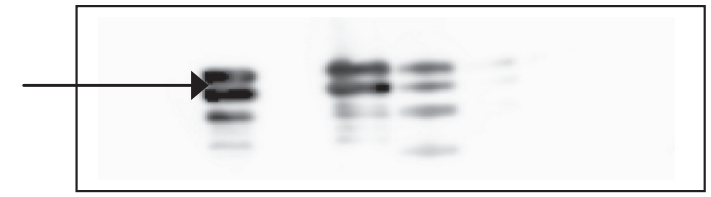

Arah 2 A2 B2 C2 D2 E2

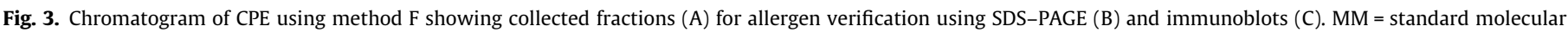
weight marker.

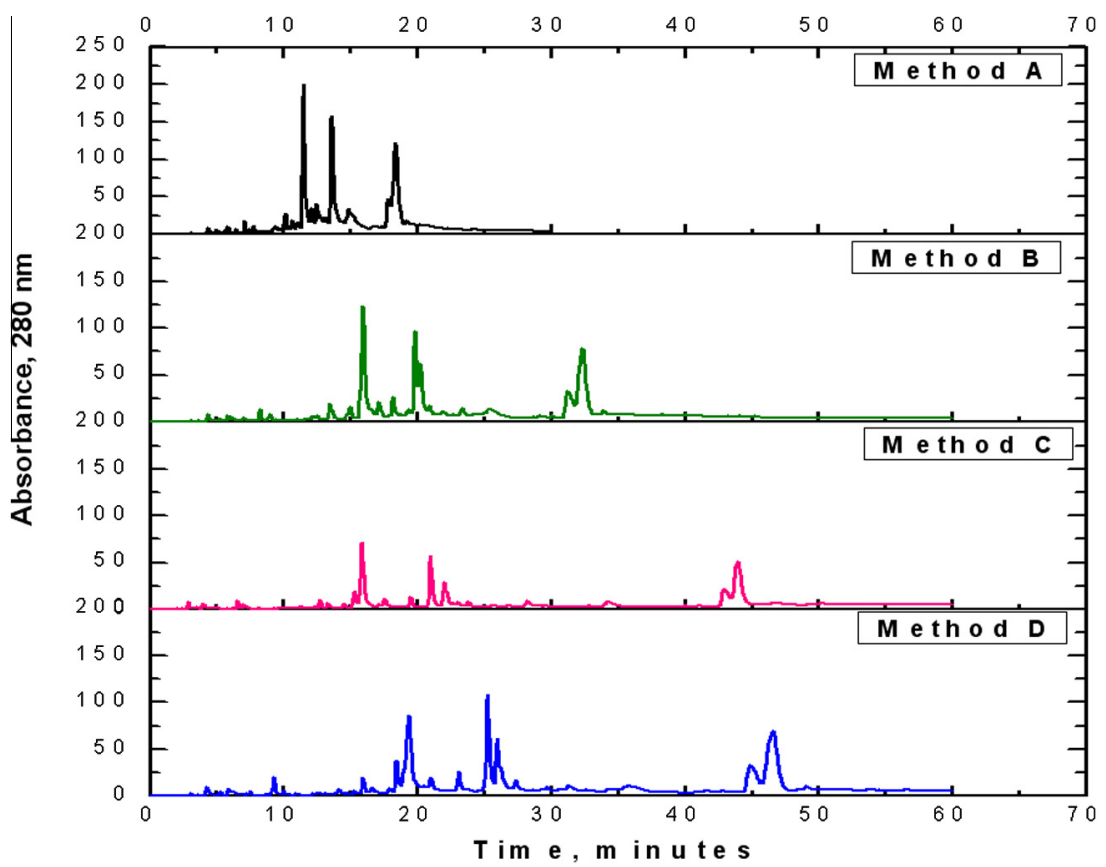

Fig. 4. HPLC chromatograms of CPE using methods A-D on C-18 column. 


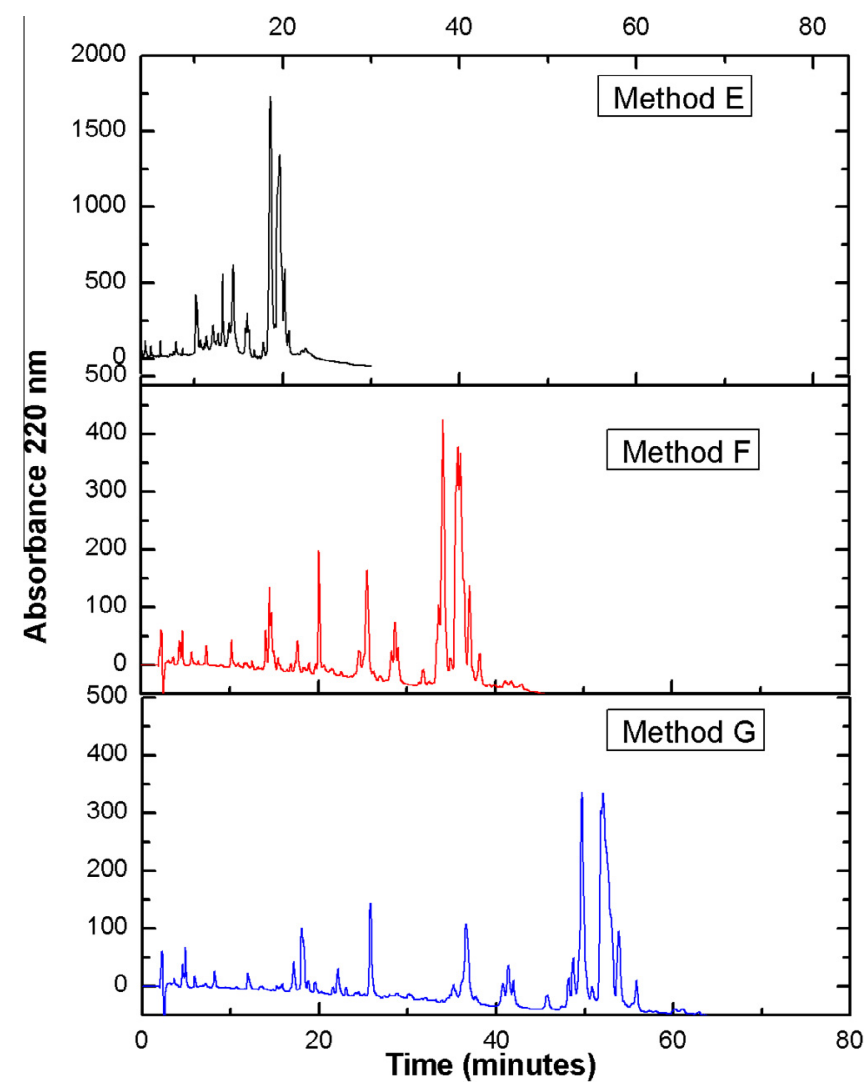

Fig. 5. HPLC chromatograms of CPE using methods E, F and $G$ on $C_{18}$ column.

immunoblotting to confirm the presence of allergens (Fig. 6). Since no protein residue was obtained after freeze-drying in fraction $\mathrm{T}$, SDS-PAGE and immunoblotting were not conducted on this fraction.

SDS-PAGE (Fig. 6B) showed that Ara h 1 was predominantly present in fraction $\mathrm{W}$ (18.1-19.1 min), Ara h 2 was predominately present in fraction $U$ (14.1-14.75 min), distinct Ara h 3 bands were observed in fraction X (19.2-20.1 min), and some faint Ara h 3 bands were also observed in fractions $W(18.1-19.1 \mathrm{~min})$ and $Y$ (20.2-21.2 min). Traces of Ara h 3 were detected in Ara h 1 fractions, possibly due to contamination from the previous runs (Fig. 6B). It is also possible that the peaks after 19 min do contain small amounts of Ara $\mathrm{h} 3$ because of tailing from the previous peaks. The immunoblotting tests conducted using chicken IgY further confirm the SDS-PAGE results (Fig. 6C and D). The immunoblot tests also confirmed that the CPE fractions collected after conducting the spike test by method $\mathrm{E}$ did contain the three allergens.

In the immunoblot of Ara h 3 (Fig. 6D), the majority of Ara h 3 was present in fractions $\mathrm{X}$ and $\mathrm{Y}$ but some binding in fraction $\mathrm{U}$ was observed. This binding in fraction $U$ was due to excess protein
Table 4

Comparison of methods E-G using C 18 column for various HPLC parameters; the retention time of allergens, peak-peak distance (resolution from the allergen peak to the preceding protein peak) and peak heights.

\begin{tabular}{|c|c|c|c|c|c|c|}
\hline \multirow[t]{2}{*}{$\begin{array}{l}\text { Method } \\
\text { Name }\end{array}$} & \multicolumn{2}{|c|}{ Retention time } & \multicolumn{2}{|c|}{$\begin{array}{l}\text { Peak-Peak } \\
\text { distance }\end{array}$} & \multicolumn{2}{|c|}{ Peak height } \\
\hline & $\begin{array}{l}\text { Ara h } \\
1\end{array}$ & $\begin{array}{l}\text { Ara h } \\
2\end{array}$ & $\begin{array}{l}\text { Ara h } \\
1\end{array}$ & $\begin{array}{l}\text { Ara h } \\
2\end{array}$ & Ara h 1 & Ara h 2 \\
\hline $\mathrm{E}$ & $18.6 \mathrm{c}$ & $14.4 \mathrm{c}$ & $0.56 c$ & $1.06 \mathrm{a}$ & $1770.2 \mathrm{a}$ & 781.77b \\
\hline $\mathrm{F}$ & $34.5 b$ & $25.6 b$ & $0.83 \mathrm{~b}$ & $0.67 b$ & 738.17b & $11411.67 a$ \\
\hline G & $49.7 a$ & $36.5 \mathrm{a}$ & $1.16 \mathrm{a}$ & $0.21 \mathrm{c}$ & $430.03 c$ & $326.0 \mathrm{c}$ \\
\hline
\end{tabular}

Means are of triplicate analysis of each sample. Each mean value with different letters $(a-d)$ in the same column indicates significant difference.

Table 5

One-way ANOVA analysis of various HPLC parameters; the retention time of allergens, peak-peak distance (resolution from the allergen peak to the preceding protein peak) and peak heights for Ara h 3 using methods P-R at $220 \mathrm{~nm}$ on a $\mathrm{C}_{18}$ column.

\begin{tabular}{llll}
\hline $\begin{array}{l}\text { Method } \\
\text { name }\end{array}$ & $\begin{array}{l}\text { Retention } \\
\text { time }\end{array}$ & $\begin{array}{l}\text { Resolution (peak-peak } \\
\text { distance) }\end{array}$ & $\begin{array}{l}\text { Peak } \\
\text { height }\end{array}$ \\
\hline E1 & $19.5 \mathrm{~h}$ & $0.00 \mathrm{~b}$ & $2668.5 \mathrm{a}$ \\
E2 & $19.7 \mathrm{~h}$ & $1.033 \mathrm{a}, \mathrm{b}$ & $2754.7 \mathrm{a}$ \\
E3 & $20.2 \mathrm{~g}$ & $0.00 \mathrm{~b}$ & $1346.4 \mathrm{~b}$ \\
F1 & $35.7 \mathrm{f}$ & $0.05 \mathrm{a}, \mathrm{b}$ & $759 \mathrm{~b}$ \\
F2 & $36.2 \mathrm{e}$ & $1.10 \mathrm{a}, \mathrm{b}$ & $711.3 \mathrm{~b}$ \\
F3 & $37.06 \mathrm{~d}$ & $0.00 \mathrm{~b}$ & $1407.8 \mathrm{~b}$ \\
G1 & $52.0 \mathrm{c}$ & $0.76 \mathrm{a}, \mathrm{b}$ & $569.2 \mathrm{~b}$ \\
G2 & $52.3 \mathrm{~b}$ & $1.7 \mathrm{a}$ & $727.3 \mathrm{~b}$ \\
G3 & $53 \mathrm{a}$ & $0.00 \mathrm{~b}$ & $577.2 \mathrm{~b}$ \\
\hline
\end{tabular}

All samples were run in triplicate. Each mean value with different letters $(a-d)$ is significantly different.

on the gel or excess antibody that was used as probe. The doublet bands seen in fraction U (Fig. 6D) correspond to Ara h 2. The Ara h 2 (fraction $\mathrm{U}$ ), CPP and $\mathrm{W}$ fractions on the gel were overloaded and hence the antibodies were binding to all of the overloaded proteins. Statistical analyses confirmed methods A-D and P-R were significantly different from one another (Tables 4 and 5).

\section{Conclusion}

The $\mathrm{C}_{12}$ column yielded two different methods for peanut allergen detection. Ara h 1 and Ara h 3 were detected at 16.3 and 16.3$17.4 \mathrm{~min}$, respectively by method $\mathrm{A}$, and Ara $\mathrm{h} 2$ was detected at 26-32 min using method F. A major drawback of the $C_{12}$ column was that Ara h 1 and Ara h 3 could not be detected at $220 \mathrm{~nm}$ due to a strong base line drift. In contrast Ara h 2 showed greater absorbance and better resolution at $220 \mathrm{~nm}$ compared to $280 \mathrm{~nm}$. The $\mathrm{C}_{18}$ column was able to overcome the drawbacks of the $\mathrm{C}_{12}$ column and the goal of developing a single method to detect all of the three peanut allergens was achieved.

Method E was chosen as the most optimal method for allergen analysis. The use of method $E$ increased sensitivity (absorbance), resolution between allergen peaks, and shortened retention time

Table 3

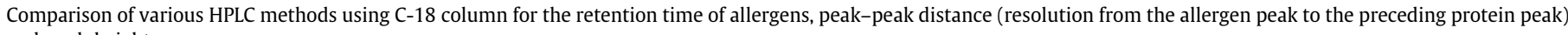
and peak heights.

\begin{tabular}{|c|c|c|c|c|c|c|c|c|c|}
\hline \multirow[t]{2}{*}{ Method } & \multicolumn{3}{|c|}{ Retention time (min) } & \multicolumn{3}{|c|}{ Resolution (peak-peak distance, min) } & \multicolumn{3}{|c|}{ Peak height (mAU) } \\
\hline & Ara h 1 & Ara h 2 & Ara h 3 & Ara h 1 & Ara h 2 & Ara h 3 & Ara h 1 & Ara h 2 & Ara h 3 \\
\hline A & $17.86 \mathrm{~d}$ & $14.9 \mathrm{~d}$ & $18.4 d$ & $0.53 c$ & $1.73 \mathrm{~b}$ & $0.87 d$ & $73.2 \mathrm{a}$ & $38.6 b$ & $254.4 a$ \\
\hline B & $31.35 c$ & $25.3 c$ & $32.2 \mathrm{c}$ & $1.10 \mathrm{~b}$ & $0.667 c$ & $1.67 \mathrm{a}$ & $76.06 a$ & $55.3 a$ & $157.4 b$ \\
\hline $\mathrm{C}$ & $42.80 \mathrm{~b}$ & $34.7 b$ & $44.0 \mathrm{~b}$ & $0.74 \mathrm{c}$ & $1.93 \mathrm{~b}$ & $1.45 b$ & $35.067 b$ & $17.8 \mathrm{~d}$ & $77.3 \mathrm{c}$ \\
\hline $\mathrm{D}$ & $45.43 a$ & $35.8 \mathrm{a}$ & $47.6 a$ & $1.6 a$ & $3.2 \mathrm{a}$ & $1.47 \mathrm{~b}$ & $34.06 \mathrm{~b}$ & $27.6 c$ & $152.1 \mathrm{~b}$ \\
\hline
\end{tabular}

Means are of triplicate analysis of each sample. Each mean value with different letters (a-d) in the same column indicates significant difference. 


\section{Method E}

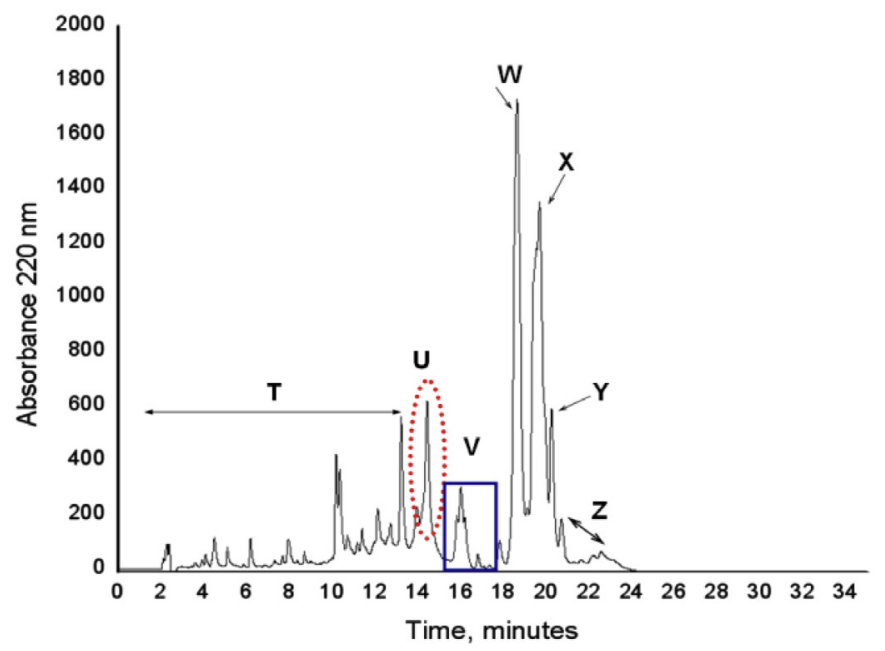

(A)

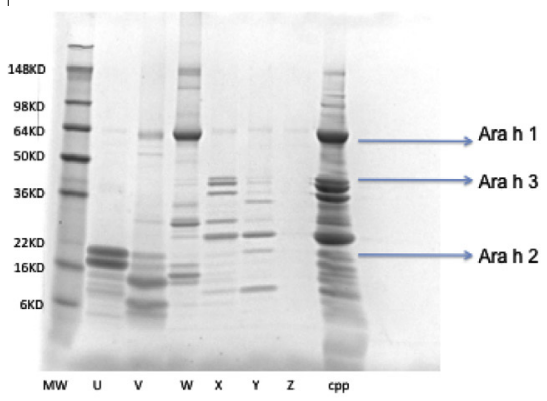

(B)

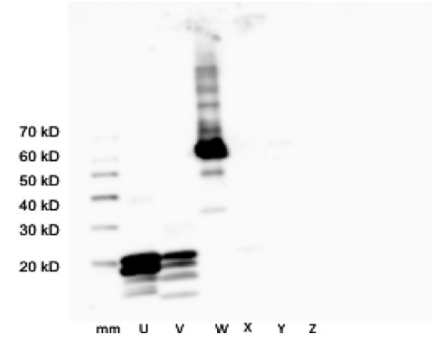

(C)

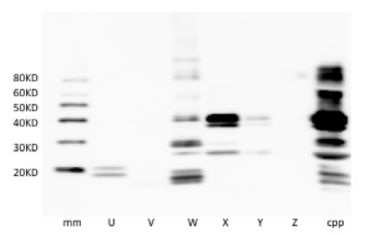

(D)

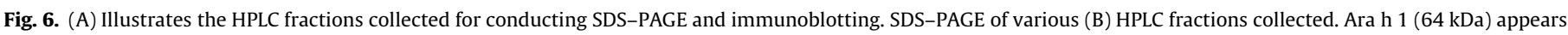

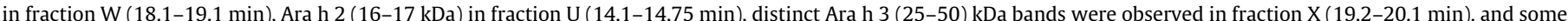

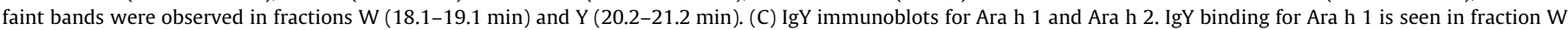

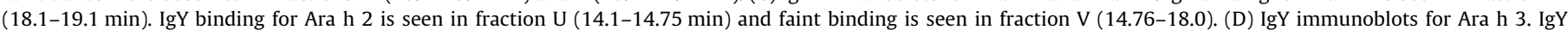
binding for Ara h 3 was seen in fractions X (19.2-20.1 min), and some faint bands were observed in fraction W (18.1-19.1 min).

for allergens. Ara h 1 and Ara h 2 eluted as individual peaks at 18.6 and $14.4 \mathrm{~min}$, respectively, and Ara h 3 elutes as a set of three peaks ranging from 19.5 to $20.2 \mathrm{~min}$. The methods were very repeatable from sample to sample and from day to day.

\section{Acknowledgements}

We would like to thank Ms. Hsiaopo Cheng for her invaluable technical support. Financial assistance from USDA and Southern California Institute of Food Technologists (SCIFT) section is greatly appreciated.

\section{References}

Burks, W. A., Sampson, H. A., \& Bannon, G. A. (1998). Review article series II peanut allergens. Allergy, 53, 725-730.
Careri, M., Elviri, L., Lagos, J. B., Mangia, A., Speroni, F., \& Terenghi, M. (2008). Selective and rapid immunomagnetic bead-based sample treatment for the liquid chromatography-electrospray ion-trap mass spectrometry detection of Ara h 3/4 peanut protein in foods. A Journal of Chromatography, 2(10), 89-94.

Chassaigne, H., Brohée, M., Nørgaard, J. V., \& van Hengel, A. J. (2007). Investigation on sequential extraction of peanut allergens for subsequent analysis by ELISA and 2D gel electrophoresis. Food Chemistry, 105(4), 1671-1681.

Chassaigne, H., Trégoat, V., Nørgaard, J. V., Maleki, S. J., \& Van Hengel, A. J. (2009). Resolution and identification of major peanut allergens using a combination of fluorescence two-dimensional differential gel electrophoresis, Western blotting and Q-TOF mass spectrometry. Journal of Proteomics, 72, 511-526.

De Jong, E. C., van Zijverden, M., Spanhaak, S., Koppelman, S. J., Pellegrom, H., \& Penninks, A. H. (1999). Identification and partial characterization of multiple major allergens in peanut proteins. Clinical and Experimental Allergy, 28(6), 743-751.

Dodo, H., Marsic, D., Callender, M., Cebert, E., \& Viquez, O. (2002). Screening 34 Peanut Introductions for Allergen Content Using ELISA. Food and Agricultural Immunology, 14, 147-154.

Francisco, M. L., \& Resurreccion, A. V. A. (2009). Development of a reversed-phase high performance liquid chromatography (RP-HPLC) procedure for the 
simultaneous determination of phenolic compounds in peanut skin extracts. Food Chemistry, 117(2), 356-363.

Koppelman, S. J., Vlooswijk, R. A., Knippels, L. M., Hessing, M., Knol, E. F., Reijsen, F. C., \& Bruijnzeel-Koomen, C. A. (2001). Quantification of major peanut allergens Ara h 1 and Ara h. in the peanut varieties Runner, Spanish, Virginia, and Valencia, bred in different parts of the world. Allergy, 56(2), 132-137.

Koppelman, J. S., Knol, E. F., Vlooswijk, R. A., Wensing, M., Knulst, A. C., Hefle, S. L., ... Piersma, S. R. (2003). Peanut allergen Ara h 3, isolation from peanuts and biochemical characterization. Allergy, 58(11), 1144-1151.

Lehmann, K., Hoffman, S., Neudecker, P., Suhr, M., Becker, W. M., \& Rosch, P. (2003). High-yield expression in Escherichia coli, purification, and characterization of properly folded major peanut allergen Ara $\mathrm{h}$ 2. Protein Expression and Purification, 31(2), 250-259.

Lehmann, K., Schweimer, K., Reese, G., Randow, S., Suhr, M., Becker, W. M., ... Rosch, P. (2006). Structure and stability of 2S albumin-type peanut allergens: Implications for the severity of peanut allergic reactions. Biochemical Journal, 395(3), 463-472.

Lifrani, A., Dubarry, M., Rautureau, M., Aatouri, N., Boyaka, P. N., \& Tome, D. (2005). Peanut lupine antibody cross reactivity is not associated to cross allergenicity in peanut sensitized mouse strains. International Immunopharmacology, 5(9), 1427-1435.

Maleki, S. J., Chung, S. Y., Champagne, E. T., \& Raufmann, J. P. (2000). The effects of roasting on the allergenic properties of peanut proteins. Journal of Allergy and Clinical Immunology, 106(4), 763-768.

Mills, E. N. C., Madsen, C., Shewry, P. R., \& Wichers, H. J. (2003). Food allergens of plant origin - Their molecular and evolutionary relationships. Trends in Food Science and Technology, 32(1), 145-156.
Moutete, H. F., Olszewski, A., Gastin, I., Namour, F., Moneret-Vautrin, D. A., \& Gueant, J. L. (1995). Purification of allergenic proteins from peanut for preparation of the reactive solid phase of a specific IgE radioimmunoassay. Journal of Chromatography B, 664, 211-217.

Pastorello, E. A., \& Trambaioli, C. (2001). Isolation of food allergens. Journal of Chromatography B, 756(1-2), 71-84.

Piersma, S. R., Gaspari, M., Helfe, S. L., \& Koppelman, S. J. (2005). Proteolytic processing of the peanut allergen Ara h 3. Molecular Nutrition and Food Research, 49(8), 744-755.

Pomes, A., Helm, R., Bannon, G., Burks, A., Tsay, A., \& Chapman, M. (2005) Monitoring peanut allergen in food products by measuring Ara h 1. Journal of Allergy and Clinical Immunology, 111(3), 641-645.

Sicherer, S. H., \& Sampson, H. A. (2007). Peanut allergy: Emerging concepts and approaches for an apparent epidemic. Journal of Allergy and Clinical Immunology. 120(3), 491-494.

Sicherer, H. S., \& Sampson, A. H. (2014). Food allergy: Epidemiology, pathogenesis, diagnosis, and treatment. Review Article Journal of Allergy and Clinical Immunology, 133(2), 291-307.

Sicherer, H. S., \& Sampson, A. H. (2010). MD New York, NY Food allergy. Journal of Allergy and Clinical Immunology, 125(2), 116-125.

Van Hengel, A. J., Anklam, E., Taylor, S. L., \& Hefle, S. L. (2007). Analysis of food allergens. Practical applications. Food toxicants analysis, 189-229.

Warner, J. O. (1999). Review article peanut allergy: A major public health issue Pediatric Allergy and Immunology, 10, 14-20.

Wen, H.-W., Borejsza-Wysocki, W., DeCory, T. R., \& Durst, R. A. (2007). Peanut allergy, peanut allergens, and methods for the detection of peanut contamination in food products. Comprehensive Reviews in Food Science, 6, 47-57. 